Vol 13, Issue 4, 2020

\title{
NEUROMUSCULAR ELECTRICAL STIMULATION FOR THE MANAGEMENT OF CHRONIC OBSTRUCTIVE PULMONARY DISEASE - PILOT STUDY
}

\author{
GANAPATHY SANKAR U, MONISHA R* \\ Department of SRM College of Occupational Therapy, SRM Institute of Science and Technology, Chennai, Tamil Nadu, India. \\ Email: dreamsfuture000@gmail.com
}

Received: 21 January 2019, Revised and Accepted: 18 February 2020

\section{ABSTRACT}

Objective: The aim of the current research is to evaluate the benefits of electrical stimulation of quadriceps for patients with chronic obstructive pulmonary disease (COPD) patients.

Methods: Ten COPD patients were willing to get enrolled in the study and after baseline screening procedure received neuromuscular electrical stimulation (NMES) with exercises for the bilateral lower limb. NMES is cost-effective and best be available to the population with COPD at the bedside.

Results: There exist a significant increase in five sit to stand test $(\mathrm{p}<0.01), 6$-min walk test $(\mathrm{p}<0.05)$, and clinical COPD questionnaire $(\mathrm{p}<0.05)$, followed by the application of NMES.

Conclusion: NMES has no impact and stress over the respiratory system and it is a gold standard exercise training modality in improving quality of life and satisfaction for people with COPD in rural locations where access to hospitalization is limited.

Keywords: Neuromuscular electrical stimulation, Chronic obstructive pulmonary disease, Dyspnea, Skeletal muscle dysfunction.

(C) 2020 The Authors. Published by Innovare Academic Sciences Pvt Ltd. This is an open access article under the CC BY license (http://creativecommons. org/licenses/by/4. 0/) DOI: http://dx.doi.org/10.22159/ajpcr.2020.v13i4.36900

\section{INTRODUCTION}

Chronic obstructive pulmonary disease (COPD) can cause mild, moderate, severe and very severe respiratory distress, and extrapulmonary manifestations. It is more prevalent in males than in females. The inability to perform exercise will enhance the physical and psychological burden and it is considered to be the predominant feature of COPD. The patients with moderate and severe COPD commonly have difficulty performing activities of daily living and this will have an impact on their workplace and another daily routine, etc. [1]. The depression and other emotional disturbances are significant findings in people with COPD which is due to the disturbances in physical function. Common medications used in the management are arformoterol (Brovana) and formoterol. These medications provide temporary relief from bronchospasm though associated with side effects [2]. Neuromuscular electrical stimulation (NMES) improves quadriceps muscle girth and enhances muscle activation. Thus NMES is a bedside therapeutic intervention to enhance the pulmonary and extrapulmonary (clinical and physiological) function in COPD patients. It is considered to be the low cost appropriate early rehabilitative strategy to use before severe muscle atrophy and weakness develops in patients with COPD. NMES is a new advanced technique to be incorporated in the management of severely disabled patients with COPD [3,4]. In the present case, NMES was applied to manage the skeletal muscle dysfunctions of COPD.

\section{METHODOLOGY}

After getting ethical clearance from the institution, information sheet which contains detailed information of the study, written in the Tamil language has been given to the participants and the primary researcher explained the procedure by which how NMES is going to be delivered and gained confidence from the participants. After getting informed consent signed from the participants, the study is initiated. Baseline examination of participants was done by following the specified criteria formulated by the previous researches [5].

The current study includes both men and women's $(n=20)$ with in the age group of 50-60 years with no exacerbations within 6 weeks before the start of baseline evaluation (October 20, 2019) and patients with Stage II COPD (GOLD criteria) and with 3+ muscle grading of for quadriceps with (MMRC) dyspnea Grade, 3 or 4 were included in the study and all the participants were with stable medical treatment and after baseline examination ten participants were excluded because of neurological disorders, previous lung surgery, and usage of long-term oxygen treatment that affects exercise performance in training and tests [6-8].

Physical examination and vitals were assessed before NMES treatment. This electrical stimulation improves physiological function in COPD patients and it is the appropriate rehabilitative strategy to prevent muscle atrophy, which is predominant in patients with COPD. NMES can be used as an alternative to interventions that impose huge burden over the cardiovascular system and it can be incorporated into the pulmonary rehabilitation program for patients with COPD. The current study employed bilateral NMES application quadriceps for 6 weeks with weekly 3 times application of NMES for a total of $40 \mathrm{~min} / \mathrm{session}$.

Symmetrical, biphasic, square-pulsed current at $50 \mathrm{~Hz}$ with a duty the cycle of $2 \mathrm{~s}$ on and $10 \mathrm{~s}$ off in the $1^{\text {st }}$ week, $5 \mathrm{~s}$ on and $25 \mathrm{~s}$ off in the $2^{\text {nd }}$ week, $10 \mathrm{~s}$ on and $30 \mathrm{~s}$ off for $3^{\text {rd }}$ and $4^{\text {th }}$ weeks, and gradually applied for 6 weeks with pulse - 300-400 microseconds was delivered. This training the protocol was used to prevent atrophy in COPD patients without exacerbating the symptoms.

\section{Ethical consideration}

The study was approved by SRM College of Occupational Therapy, SRM Institute of Science and Technology (No OT/18/67-1).

\section{RESULTS}

\section{Statistical analysis}

Table 1 contains data and was presented as mean and standard error of the mean. ${ }^{*} \mathrm{p}<0.05$ is significant, ${ }^{* *} \mathrm{p}<0.01$ is significant. The outcome values are elaborated in detail in Table 1 . There was a significant increase 
Table 1: Symptoms score and exercise capacity before and after neuromuscular electrical stimulation

\begin{tabular}{|c|c|c|c|}
\hline Outcome measures & Pre-test value (mean) & Post-test value (mean) & p-value \\
\hline Five sit to stand test (seconds) & 60 & 40 & 0.0034 \\
\hline 6 min walk test (meters) & 120 & 280 & 0.0022 \\
\hline Clinical chronic obstructive pulmonary disease questionnaire & 58 & 30 & 0.0011 \\
\hline
\end{tabular}

in five sit to stand test $(\mathrm{p}<0.01), 6$-min walk test $(\mathrm{p}<0.05)$, and clinical COPD questionnaire (CCQ) $(\mathrm{p}<0.05)$, followed by the application of NMES.

\section{DISCUSSION}

There is a Grade I evidence exists that COPD has systemic consequences with a syndrome of skeletal muscle dysfunction. However, researchers were focused on pulmonary rehabilitation of COPD patients instead of the simple and most effective rehabilitation tool NMES. Skeletal muscle dysfunction plays a key role in the symptoms and impairments in strength, endurance, and maximal exercise capacity experienced by COPD patients. Exercise capacity limitation and dyspnea usually begins with difficulty in ambulating, thus there is a need to enhance exercise capacity without eliciting dyspnea sensation in patients with COPD. This study was done with an objective to determine the efficacy of NMES over lower limb muscle training to improve the efficiency of five sit to stand the test time and 6-min walk distance in COPD patients. Highfrequency NMES is a good alternative for pulmonary rehabilitation.

The current study concludes that exercise performance, exerciseinduced symptoms of dyspnea and fatigue improved following NMES and this study adds to evidence that NMES improves exercise performance, without adding load on the cardiorespiratory system.

\section{CONCLUSION}

The outcome of data collection reveals that NMES plays a key role in the reduction of muscle atrophy in patients with COPD. The recordable change shows in the 6-min walk test, five sit to stand test (5STS), and CCQ.

\section{AUTHORS' CONTRIBUTIONS}

Dr. U. Ganapathy Sankar participated in the design of the study and performed the statistical analysis and MONISHA.R contributed to draft the manuscript and data collection work.

\section{CONFLICTS OF INTEREST}

The authors declare they have no conflicts of interest and no funding has been obtained from any source.

\section{AUTHORS FUNDING}

Self.

\section{REFERENCES}

1. Neder JA, Sword D, Ward SA, Mackay E, Cochrane LM, Clark CJ. Home-based neuromuscular electrical stimulation as a new rehabilitative strategy for severely disabled patients with chronic obstructive pulmonary disease (COPD). Thorax 2002;57:333-7.

2. Sankar UG, Monisha R. Evaluation of cardio-vascular risk in children with developmental coordination disorder in Indian context-pilot study. Res J Pharm Tech 2018;11:5405-7.

3. Sankar UG, Saritha S. A study of the prevalence of developmental coordination disorder (DCD) at Kattankulathur, Chennai. Indian J Physiother Occup Ther 2011;5:???

4. Sankar G, Monisha R. Life impact of developmental coordination disorder: Qualitative analysis of patient and therapist experiences. Biomed Pharmacol J 2019;12:491-4.

5. Shankar UG, Monisha R. Assessment of balance in children with developmental coordination disorder in Indian context. Indian J Public Health Res Dev 2019;10:67-70.

6. Monisha R, Manikumar M, Krishnakumar A. Evaluating the effectiveness of phonophoresis by piroxicam and dimethyl sulfoxide for women with osteoarthritis knee joint. Asian J Pharm Clin Res 2018;11:329-31.

7. Solanki ND, Patel A, Patel L. In vitro evaluation of anti-cancer potential of A3 adenosine receptor agonist on a549 human lung cancer cell line. Int J Pharm Pharm Sci 2019;11:106-8.

8. Muhas C, Kumar PR, Raja D. Etiological factors for the development of lung cancer in non-smokers: An overview. Int J Pharm Pharm Sci 2019;11:10-6. 